\title{
Quantum-chemical studies of the nitration of benzazoles
}

\author{
Martin Breza ${ }^{a}$ and Viktor Milata* ${ }^{b}$ \\ ${ }^{a}$ Department of Physical Chemistry, Faculty of Chemical and Food Technology, Slovak \\ University of Technology, Radlinského 9, SK-812 37 Bratislava, Slovak Republic \\ ${ }^{b}$ Department of Organic Chemistry, Faculty of Chemical and Food Technology, Slovak \\ University of Technology, Radlinského 9, SK-812 37 Bratislava, Slovak Republic \\ E-mail: martin.breza@stuba.sk; viktor.milata@stuba.sk
}

\section{Dedicated to Professor José Elguero on the occasion of his $70^{\text {th }}$ birthday}

(received 07 Dec 04; accepted 27 Jan 05; published on the web 03 Feb 05)

\begin{abstract}
The $\mathrm{H}$-tautomers of benzotriazole, benzimidazole, and their $\mathrm{N}$-methyl- derivatives, as well as of their cations have been investigated by using the MP2/cc-pVDZ treatment. The atomic reactivity indices for electrophilic reactions (nitration) in the optimized geometries of the compounds under study have been evaluated as the electron density of the highest occupied molecular orbital. Both the benzotriazoles and their protonated cations prefer nitration in the 4- and/or 7-positions in agreement with experimental data. Only the more stable tautomers of $1 H$-benzimidazole nitrated in the 6-position, and the $3 H$-protonated cations of 1,3- $H$-benzimidazolium and 1-methyl-3Hbenzimidazolium nitrated in the 5- and 6-positions, in full agreement with experiment. The results imply the importance of the protonated benzdiazolium cations for the nitration.
\end{abstract}

Keywords: Nitration, benzotriazole, benzimidazole, $N$-methylbenzotriazole, 1methylbenzimidazole

\section{Introduction}

Benzimidazole and benzotriazole are isoelectronic tautomeric heterocyclic systems which are frequently exploited in organic synthesis, having applications in many areas of life, especially owing to their biological activity. ${ }^{1-3}$ Nitro- derivatives are very important in organic synthesis, mainly owing to the enormous quantity of intermediates prepared by reduction, ${ }^{4}$ but also to their interesting types of reactions. ${ }^{5}$

Many derivatives bearing a nitro group play an important role because of their bioactivity, such as the antibiotic chloramphenicol ${ }^{6}$ or the antifungal pyrrolnitrin. ${ }^{7}$ Nitro- heterocycles such as the 2-nitroimidazoles (e.g., misonidazole) were originally developed as radio-sensitizers ${ }^{8}$ or 
hypoxia-selective anti-tumor agents. ${ }^{9}$ Some 2-phenylbenzotriazoles have been found to be applicable as fluorescent hydrophobic probes. ${ }^{10,11}$

A short survey of the nitration of selected benzazoles is given in Table 1 (for the numbering of the benzazole ring see Scheme 1). It was described in the literature a long time ago that the nitration of benzotriazole gives 4- or 7- nitrobenzotriazole, whereas the nitration of benzimidazole occurs at the 5- or 6-position. This discrepancy is especially striking since we are considering two isoelectronic systems.

Nitrations of benzazoles are generally effected using concentrated $(65 \%)$ to fuming $(100 \%)$ nitric acid, generally at temperatures between $0-5{ }^{\circ} \mathrm{C}$. In the nitration of the benzoxazole the azole ring is opened during the reaction. ${ }^{12}$ In the nitration of 2,1,3-benzthiadiazole the structure of product was originally assigned wrongly; the results were reinvestigated and the correct structure confirmed using straightforward unambiguous synthesis. ${ }^{14}$

Recent $a b$ initio quantum-chemical studies of simple benzotriazole and benzimidazole molecules ${ }^{15-37}$ focus on their optimal geometries, the relative stability of the $H$-tautomers, electronic structures, and spectroscopic properties. Unfortunately, their reactivity remains outside the main research direction in this field. The generalized reactivity studies (such as the pioneering work of Brown and Heffernan) ${ }^{38}$ have not been repeated at the $a b$ initio level of theory (with some exceptions such as the study on the nitration of nitro-1H-benzotriazole derivatives containing electron withdrawing substituents in the positions ortho- and meta- to the nitro-group) ${ }^{39}$ despite new reactivity concepts having been developed by theoretical chemists. The frontier electron density (FED) treatment of Fukui ${ }^{40}$ is based on the evaluation of reactivity indices based on the electron density of the highest occupied molecular orbitals (HOMO) for the electrophilic attacking reagents whereas its formal analogue for the (vacant) lowest unoccupied molecular orbitals (LUMO) is used for the nucleophilic attacking reagents. This treatment has been used widely in semi-empirical methods of quantum chemistry but is also valid at more sophisticated levels of theory. Nevertheless, the simpler (but more time-consuming) treatment based on the geometry optimization of possible reaction products and their energy comparison is preferred nowadays, as the more powerful computers are available. It must be mentioned that Fukui's treatment ${ }^{40}$ supposes the determining role of the first reaction step in the reaction as a whole. Another shortcoming of this treatment is that the use of unbalanced basis sets (with large numbers of polarization and/or diffusion functions such as in the $6-31++\mathrm{G}^{* *}$ one) may bring unreliable results (owing to the non-physical origin of the augmented functions). This might be the main reason why the less experienced scientists prefer the alternative treatments.
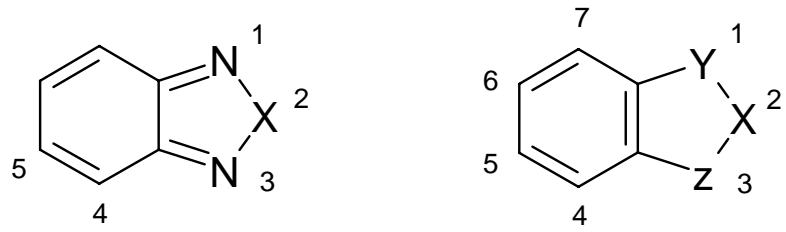

Scheme 1. Numbering of benzoazoles. 
Table 1. Nitrations of benzazoles

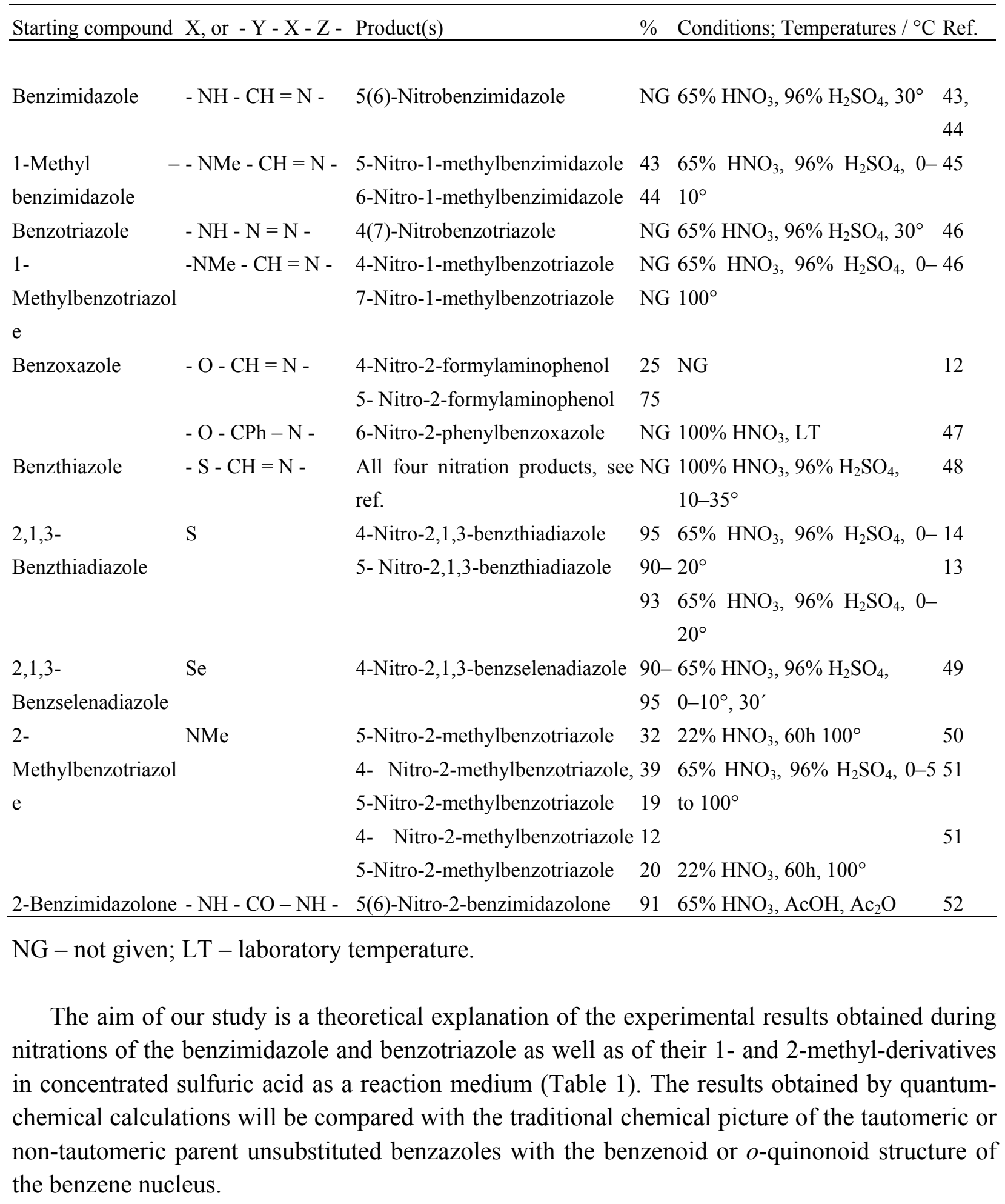




\section{Results and Discussion}

The recent classical chemical picture of benzotriazole- and benzimidazole- nitration consists in the tautomerism of these two systems. Benzotriazole itself could exist in two tautomeric forms, the $1 H$-benzotriazole (1a) and the less basic $2 H$-benzotriazole (1b):

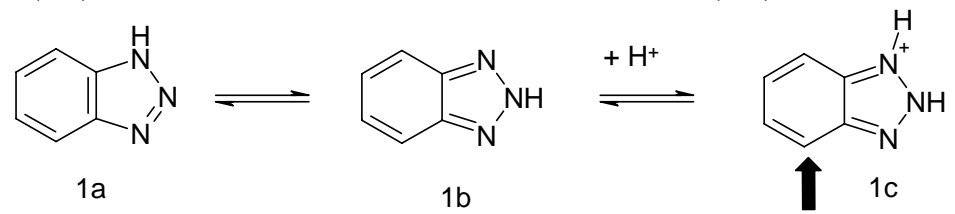

The second of these has a non-aromatic, $o$-quinonoid structure which could also be found in 2,1,3-benzoselenadiazole or 2,1,3-benzothiadiazole. These two heterocycles are nitrated regioselectively in the 4-position, i.e., to the position ortho- to the protonated heterocyclic ring. There is a conjugated diene $\pi$-system of non-heterocyclic part of the molecule. It is polarized by the protonated azole ring and therefore the nitration produces ortho-nitro- derivatives to the benzazole ring, i.e., to the 4-positions. The tautomerism of 1-methylbenzotriazole (2) is restricted by the presence of the methyl group in the 1-position, but the protonation produces the isoelectronic non-aromatic $o$-quinonoid species $\mathbf{1 c}, \mathbf{2} \mathbf{b}$ and $\mathbf{3 b}$, respectively:

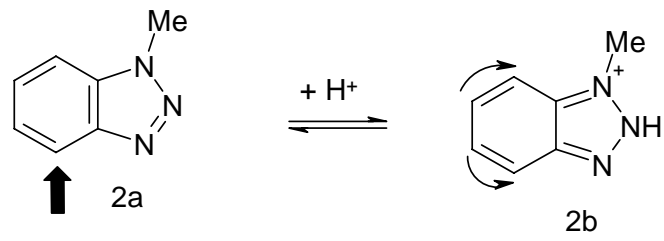

$3 \mathbf{b}$ is produced by the protonation of the isomeric 2-methylbenzotriazole, which is nitrated to give a mixture of 4- and 5- isomers or only the 5-isomer for the case of the use of diluted nitric acid without concentrated sulfuric acid. This fact could be explained by the lower basicity of 2methylbenzotriazole derivatives: ${ }^{41}$

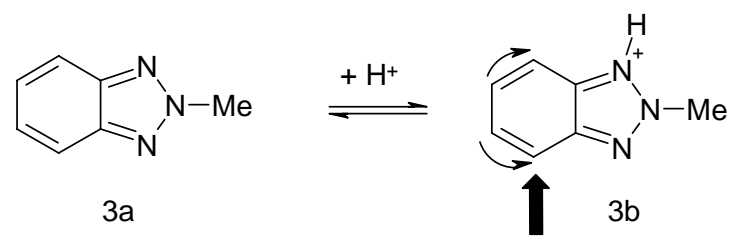

Benzimidazole (1) could also exist like the $1 H$ - (4a) or $2 H$ - (4b) tautomer, but the equilibrium is predominantly shifted to the $1 \mathrm{H}$-tautomer. Therefore, $\mathrm{o}$-quinonoid non-aromatic species $\mathbf{4 b}$ and its protonated analogue $\mathbf{4 c}$ are not present. The protonated tautomer $1 \mathrm{H}$-produces a species $\mathbf{4 d}(=\mathbf{4 e})$ with an aromatic benzene ring: 


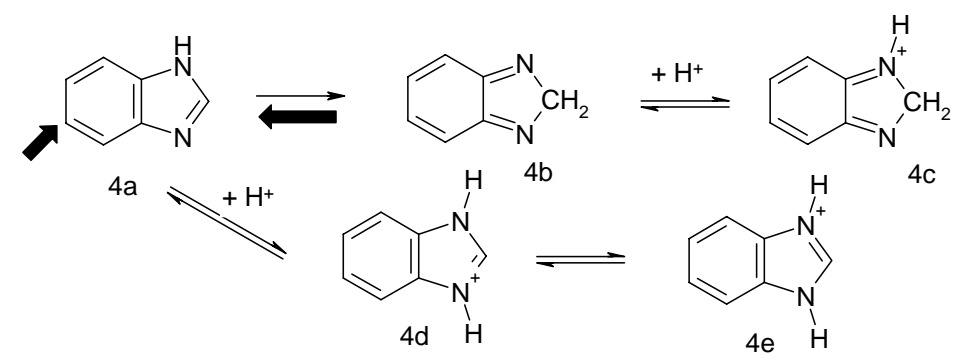

The protonated imidazole ring is not so strong an electron acceptor as in the case of the triazole ring, and the aromaticity of the benzene ring is not violated. Thus, the formation of a 5(6)-nitro- isomer only may be explained formally as due to the imidazole ring's acting as a meta- orienting substituent. The same situation occurs in the case of the nitration of 1methylbenzotriazole:

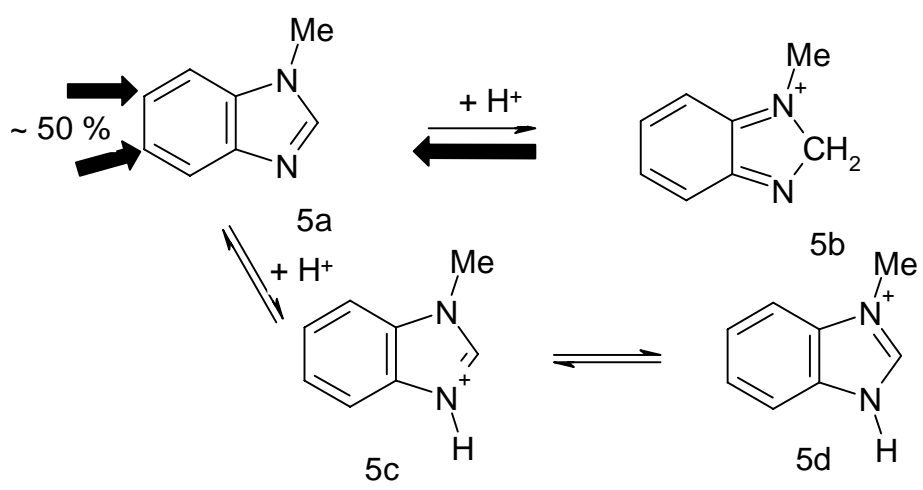

An equimolar mixture of 5- and 6-nitro-1-methylbenzimidazoles is formed. Similar nitration products are given when 2-methyl- or 2-alkyl- benzimidazole, ${ }^{42}$ 2-amino-1-methylbenzimidazole, or 2-phenylbenzimidazole is nitrated. In the case of nitration of the last substrate, the phenyl ring is not nitrated.

Our quantum-chemical treatment is based on the comparison of total energies and HOMO FED reaction indices only because other electronic structure- and geometry characteristics of the compounds under study have been investigated by other authors ${ }^{15-37}$ and are not necessary for our purposes. The reactivity indices for the carbon atoms in the $3 \mathrm{a}-$ and $7 \mathrm{a}$ - positions are not presented because the next reaction steps (after the predicted first one) in these positions are highly improbable. If comparing the nitration and protonation at the remaining positions (presented in the Tables), their rates are also modified by the next reaction steps. Thus, the higher probability of nitration than protonation at the benzene ring, and their reverse relation at its azole neighbor may be assumed formally.

The problem of the relative stability of the benzotriazole tautomers in real systems is not fully solved yet. Reasonable arguments for the higher stability of $1 \mathrm{H}$-benzotriazole (1a) $)^{18,24,29,32,34}$ as well as of $2 H$-benzotriazole (1b) ${ }^{15,16,17,26,30}$ may be found in the literature. From our point of view, it is important that their total energy difference is so small (ca $3 \mathrm{kcal} / \mathrm{mol}$ ) that they may coexist in the solution (Table 2). Moreover, their HOMO FED reactivity indices 
indicate the preferred 4(7)-position for nitration in agreement with experimental data. ${ }^{46}$ The same holds for their protonated form (1c). However, our results indicate that the protonation of both benzotriazole tautomers in the 2-position is highly improbable. Thus, the protonated form (1c) may be formed from the (1b) tautomer by the more probable protonation in the 1(3)- position only.

An analogous situation (Table 3) may be observed in the case of methylbenzotriazoles (2a) and (3a) as well as their protonated forms (2b) and (3b). In all cases, the nitration in 4- and 7positions is preferred (in agreement with experimental data ${ }^{46}$ ) whereas the protonation in 2position is highly improbable. Thus the possible existence of 2-methyl- $1 \mathrm{H}$-benzotriazolium (3b) might be explained by its formation from its less stable 1-methyl-analogue (2b).

Table 2. The total energy $\mathrm{E}_{\text {tot }}$ and HOMO FED indices of benzotriazoles

\begin{tabular}{llll}
\hline Compound & $1 H$-Benzotriazole & $2 H$-Benzotriazole & $1,2-H$-Benzotriazolium \\
\hline & $\mathbf{1 a}$ & $\mathbf{1 b}$ & $\mathbf{1 c}$ \\
E $_{\text {tot }}$ (a.u.) & -394.72265 & -394.72750 & -395.06216 \\
HOMO FED & & & \\
1- N & 0.248 & 0.250 & 0.170 \\
2- N & 0.005 & 0.001 & 0.002 \\
3- N & 0.047 & 0.250 & 0.090 \\
4- C & $\mathbf{0 . 3 5 6}$ & $\mathbf{0 . 3 5 4}$ & $\mathbf{0 . 4 2 7}$ \\
5- C & 0.265 & 0.150 & 0.290 \\
6- C & 0.046 & 0.150 & 0.038 \\
7- C & $\mathbf{0 . 3 9 2}$ & $\mathbf{0 . 3 5 4}$ & $\mathbf{0 . 4 0 3}$ \\
\hline
\end{tabular}

Table 3. The total energy, $\mathrm{E}_{\text {tot }}$ and HOMO FED indices of methylbenzotriazoles

\begin{tabular}{|c|c|c|c|c|}
\hline Compound & $\begin{array}{l}\text { 1-Methyl- } \\
\text { benzotriazole }\end{array}$ & $\begin{array}{l}\text { 1-Methyl-2H- } \\
\text { benzotriazolium }\end{array}$ & $\begin{array}{l}\text { 2-Methyl- } \\
\text { benzotriazole }\end{array}$ & $\begin{array}{l}\text { 2-Methyl-1H- } \\
\text { benzotriazolium }\end{array}$ \\
\hline & $2 a$ & $2 \mathbf{b}$ & $3 \mathbf{a}$ & $3 \mathbf{b}$ \\
\hline $\mathrm{E}_{\text {tot }}$ (a.u.) & -433.90402 & -434.25087 & -433.91027 & -434.25434 \\
\hline \multicolumn{5}{|l|}{ HOMO FED } \\
\hline $1-\mathrm{N}$ & 0.295 & 0.204 & 0.252 & 0.165 \\
\hline $2-\mathrm{N}$ & 0.004 & 0.002 & 0.001 & 0.002 \\
\hline $3-\mathrm{N}$ & 0.174 & 0.112 & 0.249 & 0.090 \\
\hline 4- $\mathrm{C}$ & 0.331 & 0.412 & 0.352 & 0.423 \\
\hline 5- $\mathrm{C}$ & 0.248 & 0.262 & 0.155 & 0.282 \\
\hline 6- $\mathrm{C}$ & 0.050 & 0.050 & 0.143 & 0.039 \\
\hline 7- $\mathrm{C}$ & 0.369 & 0.404 & 0.354 & 0.407 \\
\hline
\end{tabular}


The problem of benzimidazoles' nitration (Table 4) is not so simple. The preferred nitration site of the $1 \mathrm{H}$-tautomer (4a) is the 6-position, in agreement with experimental data, ${ }^{43-45}$ whereas the less stable (ca $30 \mathrm{kcal} / \mathrm{mol}$ ) $2 \mathrm{H}$-tautomer (4b) prefers the 4(7)-position. If the protonated benzimidazolium cations are considered, the less stable (ca $40 \mathrm{kcal} / \mathrm{mol}$ ) 1,2-H-tautomer (4c) prefers the positions 4, 5 and 7, whereas the more stable 1,3-H-benzimidazolium (4d) prefers the experimentally confirmed ${ }^{43-45} 5(6)$-position. The problem is in the benzimidazolium cation formation. Whereas the less stable 1,2-H-tautomer (4c) may arise from both imidazole tautomers, the formation of 1,3-H-benzimidazolium (4d) is less probable, owing to the very small reactivity index of $1 \mathrm{H}$-imidazole (4a) at the 3 -position (Table 4).

In 1-methyl-benzimidazole (5a) the nitration in the 6-position is preferred (Table 5) whereas nearly equal amounts of 5- and 6-nitro-derivatives are obtained experimentally. ${ }^{45}$

Table 4. The total energy $E_{\text {tot. }}$ and HOMO FED indices of benzimidazoles

\begin{tabular}{|c|c|c|c|c|}
\hline Compound & $\begin{array}{l}1 H- \\
\text { Benzimidazole }\end{array}$ & 2H-Benzimidazole & $\begin{array}{l}\text { 1,2-H- } \\
\text { Benzimidazolium }\end{array}$ & $\begin{array}{l}\text { 1,3-H- } \\
\text { Benzimidazolium }\end{array}$ \\
\hline & $4 a$ & $4 b$ & $4 c$ & 4d \\
\hline $\mathrm{E}_{\text {tot }}$ (a.u.) & -378.73720 & -378.68393 & -379.04535 & -379.11353 \\
\hline \multicolumn{5}{|l|}{ HOMO FED } \\
\hline $1-\mathrm{N}$ & 0.001 & 0.248 & 0.191 & 0.015 \\
\hline 2- $C$ & 0.272 & 0.001 & 0.001 & 0.206 \\
\hline $3-\mathrm{N}$ & 0.098 & 0.248 & 0.120 & 0.016 \\
\hline 4- $C$ & 0.089 & 0.305 & 0.392 & 0.007 \\
\hline 5- $C$ & 0.095 & 0.182 & 0.340 & 0.322 \\
\hline 6- $C$ & 0.361 & 0.183 & 0.052 & 0.322 \\
\hline 7- $\mathrm{C}$ & 0.042 & 0.305 & 0.378 & 0.007 \\
\hline
\end{tabular}

Table 5. The total energy $E_{\text {tot }}$ and HOMO FED indices of 1-methylbenzimidazoles

\begin{tabular}{llll}
\hline Compound & $\begin{array}{l}\text { 1-Methyl- } \\
\text { benzimidazole }\end{array}$ & $\begin{array}{l}\text { 1-Methyl-2H- } \\
\text { benzimidazolium }\end{array}$ & $\begin{array}{l}\text { 1-Methyl-3H- } \\
\text { benzimidazolium }\end{array}$ \\
\hline & $\mathbf{5 a}$ & $\mathbf{5 b}$ & $\mathbf{5 c}, \mathbf{5 d}$ \\
E & -418.23042 & -418.29709 \\
HOMO FED & & & \\
1- N & 0.001 & 0.225 & 0.015 \\
2- C & 0.272 & 0.000 & 0.167 \\
3- N & 0.104 & 0.141 & 0.012 \\
4- C & 0.093 & 0.369 & 0.006 \\
5- C & 0.093 & 0.311 & 0.232 \\
6- C & 0.360 & 0.064 & 0.222 \\
7- C & 0.040 & 0.371 & 0.004 \\
\hline
\end{tabular}


The nearly equal reaction indices for the nitration in the 5- and 6-positions may be attributed to 1-methyl-3H-benzimidazolium (5c, 5d). Its less stable (ca $40 \mathrm{kcal} / \mathrm{mol}) 2 \mathrm{H}$-tautomer (5b) prefers nitration in the 4-, 5- and 7-positions. It must be mentioned that the 1-methylbenzimidazole (5b) in the 2-position is more probable than in the 3-position. This means that the rate of the less stable 1-methyl-2H-benzimidazolium's (5b) formation is higher than of its more stable $3 \mathrm{H}$-tautomer $(\mathbf{5 c}, \mathbf{5 d})$. The higher reaction rate corresponds to the lower reaction barrier (and vice versa) and so the concentration equilibrium of both cations in the solution must be obtained by their mutual interconversion. The agreement of experimental data with the reactivity indices of the protonated 1-methyl-3H-benzimidazolium (5c, 5d) and not of the neutral 1methyl-benzimidazole (5a) confirms the important role of protonated cations for the nitration of benzazoles. $^{39}$

Finally, it may be concluded that many principles of the above-mentioned classical picture are confirmed by the results of high-level quantum-chemical calculations. The theoretical predictions based on Fukui reaction indices ${ }^{40}$ of the systems under study are in excellent agreement with experimental data. The predictions for the benzotriazoles are equal for all their tautomers as well as all tautomers of their protonated cations. On the other hand, only the more stable tautomers of $1 \mathrm{H}$-benzimidazole nitrated in the 6-position, as well as of 1,3- $\mathrm{H}$ benzimidazolium and 1-methyl-3H-benzimidazolium cations nitrated in the 5- and 6-positions are in full agreement with experiment. This implies the importance of the protonated benzdiazolium cations for the nitration.

Similar conclusions based on Fukui's rules ${ }^{40}$ also hold for other electrophilic substitutions. Nevertheless, the extrapolation of our results to the similar types of benzodiazoles must be treated very carefully (see Table 1). Further theoretical studies in this field are desirable.

\section{Experimental Section}

General Procedures. Using the Gaussian03 program package, ${ }^{53}$ the optimal geometries of the compounds under study are investigated within the standard MP2 treatment with standard accuracy parameters and Dunning's correlation-consistent cc-pVDZ basis sets. ${ }^{54}$ To compare the reactivity indices for the reaction with electrophilic attacking reagents, the frontier electron densities (FED) for the highest occupied molecular orbitals (HOMO) of individual atoms according to Fukui ${ }^{40}$ were evaluated using the doubled sum of squared LCAO coefficients.

\section{Acknowledgments}

The authors thank the Slovak grant agency for financial support (grants No. 1/9254/02 and 1/0058/03). 


\section{References}

1. Elguero, J.; Marzin, C.; Katritzky, A.R.; Linda, P. The Tautomerism of Heterocycles, Academic Press: New York, 1976.

2. Katritzky, A.R.; Karelson, M.; Harris, P.A. Heterocycles 1991, 32, 329.

3. Advances in Heterocyclic Chemistry, Katritzky, A.R., Ed.; Academic Press: San Diego, 2000; Vol. 76.

4. Hudlicky, M. Reductions in Organic Chemistry, Ellis Horwood Ltd.: Chichester, 1984.

5. Murashima, T.; Fujita, K.; Ono, K.; Ogawa, T.; Uno, H.; Ono, N. J. Chem. Soc. Perkin Trans. 1 1996, 1403.

6. Vats, S.; Stuttard, C.; Vining, L.C. J. Bacteriol. 1987, 169, 3809.

7. Kirner, S.; van Pée, K.-H. Angew. Chem., Int. Ed. 1994, 33, 352.

8. Adams, G.E.; Stratford, I.J. Biochem. Pharmacol. 1986, 35, 71.

9. Denny, W.A.; Atwell, G.J.; Roberts, P.B.; Anderson, R.F.; Boyd, M.; Lock, C.J.L.; Wilson, W.R. J. Med. Chem. 1992, 35, 4832.

10. Narita, S.; Kitagawa, T. Chem. Pharm. Bull. 1989, 37, 1005.

11. Narita, S.; Tasaki, T.; Kitagawa, T. Chem. Pharm. Bull. 1989, 37, 1009.

12. Llinares, J.; Galy, J.-P.; Faure, R.; Vincent, E.-J.; Elguero, J. Can. J. Chem. 1979, 57, 937.

13. Khaleckij, A. M.; Pesin, B. G. Zh. Obsch. Khim. 1950, 20, 1914.

14. Komin, A. P.; Carmack, M. J. Heterocycl. Chem. 1975, 12, 829.

15. Tomas, F.; Catalan, J.; Perez, P.; Elguero J. J. Org. Chem. 1994, 59, 2799.

16. Palmer, M.H.; Kurshid, M.M.P.; Rayner, T.J.; Smith, J.A.S. Chem. Phys. 1994, 182, 27.

17. Fischer, G.; Cao, X.L.; Purchase, R.L. Chem. Phys. Lett. 1996, 262, 689.

18. Negri, F.; Caminati, W. Chem. Phys. Lett. 1996, 260, 119.

19. Bigotto, A.; Pandey, A.N.; Zerbo, C. Spectroscopy Lett. 1996, 29, 511.

20. Schoone, K.; Smets, J.; Houben, L.; Van Bael, M.K.; Adamowicz, L.; Maes, G. J. Phys. Chem. A 1998, 102, 4863.

21. Roth, W.; Jacoby, C.; Westphal, A.; Schmitt, M. J. Phys. Chem. A 1998, 102, 3048.

22. Barsky, D.; Kool, E.T.; Colvin, M.E. J. Biomol. Struct. Dynam. 1999, 16, 1119.

23. Torrent, M.; Musaev, D.G.; Morokuma, K.; Ke S.C.; Warncke, K. J. Phys. Chem. B 1999, $103,8618$.

24. Roth, W.; Spangenberg, D.; Janzen, C.; Westphal, A.; Schmitt, M. Chem. Phys. 1999, 248, 17.

25. Rademacher, P.; Kowski, K.; Katritzky, A.R.; Denisenko, S.N. J. Mol. Struct. 1999, 513, 47.

26. Jacoby, C.; Roth, W.; Schmitt, M. Appl. Phys. B 2000, 71, 643.

27. Serrano-Andres, L.; Borin, A.C. Chem. Phys. 2000, 262, 267.

28. Borin, A.C.; Serrano-Andres, L. Chem. Phys. 2000, 262, 253.

29. Wang, H.; Burda, C.; Persy, G.; Wirz, J. J. Am. Chem. Soc. 2000, 122, 5849.

30. Schmitt, M.; Plutzer, C.; Kleinermanns, K. Phys. Chem. Chem. Phys. 2001, 3, 4218.

31. Morsy, M.A.; Al-Khaldi, M.A.; Suwaiyan, A. J. Phys. Chem. A 2002, 106, 9196. 
32. Jagerovic, N.; Jimeno, M.L.; Alkorta, I.; Elguero, J.; Claramunt, R.M. Tetrahedron 2002, 58, 9089.

33. Wiench, J.W.; Koprowski, M.; Stefaniak, L.; Webb, G.A. Polish J. Chem. 2002, 76, 525.

34. Ueno, L.T.; Ribeiro, R.O.; Rocha, M.S.; Suarez-Iha, M.E.V.; Iha, K.; Machado, F.B.C. J. Mol. Struct. (Theochem) 2003, 664, 207.

35. Ludwig, V.; Coutinho, K.; Borin, A.C.; Canuto, S. Int. J. Quant. Chem. 2003, 95, 572.

36. Borin, A.C.; Serrano-Andres, L.; Ludwig, V.; Canuto, S. Phys. Chem. Chem. Phys. 2004, 3, 353.

37. Fowler, P.W.; Soncini, A. Polycycl. Arom. Compds. 2004, 24, 353.

38. Brown, R.D.; Heffernan, M.L. J. Chem. Soc. 1956, 4288.

39. McHugh, C.J.; Tackley, D.R.; Graham, D. Heterocycles 2002, 57, 1461.

40. Fukui, K.; Yonezawa, T.; Nagata, Ch.; Shingu, H. J. Chem. Phys. 1954, 22, 1433.

41. Schellhammer, C.W.; Schroeder, J.; Joop, N. Tetrahedron 1970, $26,497$.

42. Ambacheu, K.D.; Pleshakov, V.G.; Baatkh, B.S.; Zvolinskii, M.D.; Kharlamova, M.D.; Obynochnyi, A.A.; Prostakov, N.S. Chem. Heterocycl. Compds. 2000, 36, 421.

43. Bamberger, E.; Berlé, B. Liebigs Ann. 1893, 273, 340.

44. Fischer, O.; Hess, W. Ber. 1903, 36, 3968.

45. Milata, V.; Ilavský, D. Bull. Soc. Chim. Belg. 1996, 105, 213.

46. Fries, K.; Güterbock, H.; Kühn, H. Liebigs Ann. 1934, 511, 229.

47. Stephens, F. F.; Bower, D. Jr. J. Chem. Soc. 1949, 2971.

48. Ward, E.R.; Poesche, W.H. J. Chem. Soc. 1961, 2825.

49. Sawicki, E.; Carr A. J. Org. Chem. 1957, 22, 503.

50. Wiley, H.R.; Hussung, K.F. J. Am. Chem. Soc. 1957, 79, 4395.

51. Kamel, M.; Sherif, S.; Kamel, M.M. Tetrahedron 1964, 20, 211.

52. Schindlbauer, H.; Kwiecinski W. Monatsh. Chem. 1976, 107, 1307.

53. Frisch, M.J.; Trucks, G.W.; Schlegel, H.B.; Scuseria, G.E.; Robb, M.A.; Cheeseman, J.R.; Montgomery, J.A. Jr.; Vreven, T.; Kudin, K.N.; Burant, J.C.; Millam, J.M.; Iyengar, S.S.; Tomasi, J.; Barone, V.; Mennucci, B.; Cossi, M.; Scalmani, G.; Rega, N.; Petersson, G.A.; Nakatsuji, H.; Hada, M.; Ehara, M.; Toyota, K.; Fukuda, R.; Hasegawa, J.; Ishida, M.; Nakajima, T.; Honda, Y.; Kitao, O.; Nakai, H.; Klene, M.; Li, X.; Knox, J. E.; Hratchian, H.P.; Cross, J.B.; Adamo, C.; Jaramillo, J.; Gomperts, R.; Stratmann, R.E.; Yazyev, O.; Austin, A.J.; Cammi, R.; Pomelli, C.; Ochterski, J. W.; Ayala, P.Y.; Morokuma, K.; Voth, G.A.; Salvador, P.; Dannenberg, J.J.; Zakrzewski, V.G.; Dapprich, S.; Daniels, A.D.; Strain, M.C.; Farkas, O.; Malick, D. K.; Rabuck, A.D.; Raghavachari, K.; Foresman, J.B.; Ortiz, J.V.; Cui, Q.; Baboul, A.G.; Clifford, S.; Cioslowski, J.; Stefanov, B.B.; Liu, G.; Liashenko, A.; Piskorz, P.; Komaromi, I.; Martin, R.L.; Fox, D.J.; Keith, T.; Al-Laham, M.A.; Peng, C.Y.; Nanayakkara, A.; Challacombe, M.; Gill, P.M. W.; Johnson, B.; Chen, W.; Wong, M. W.; Gonzalez, C.; Pople, J. A. Gaussian 03, Revision C.1, Gaussian, Inc., Pittsburgh PA 2003.

54. Woon, D.E.; Dunning, T.H. Jr. J. Chem. Phys. 1993, 98, 1358. 